\title{
Eksplorasi dan analisis kondisi perkerasan jalan pada jembatan rangka baja Soekarno-Hatta Malang pada bulan Maret 2015 menggunakan metode ground penetrating radar (GPR)

\author{
Rabbiatul Adawiyah, Daeng Achmad Suaidi*, Markus Diantoro \\ *Penulis korespondensi, Surel: daeng.achmad.fmipa@um.ac.id
} \\ Universitas Negeri Malang, Jl. Semarang No. 5 Malang, Jawa Timur, Indonesia
}

Paper received: Paper received: 01-01-2022; revised: 15-01-2022; accepted: 31-01-2022

\begin{abstract}
This research that purpose to explore and analyz the structure condition of pavement on the Soekarno-Hatta's Malang truss bridge by using GPR method. GPR is used to knowing type of material objects based on dielectric constant of every materials, and to showing deformation, cracking, release structure, and water seepage. Data collected by observation techniques and retrieval of data sanples at 101 point of the track. Analysis starts from the stage of processing by using Ms.Excel, notepad, paint, software GeoScan32, and interpreted using software Surfer 9.0. The result is showing that the road pavement structure consists of a flexible pavement asphalt and rigid pavement concrete by identified the type of material is dry asphalt, wet asphalt, dry concrete, wet concrete, and air on surface. Deformation occurred in all of track pavement and there are a few sample points are experienced track surface defect such as cracks and release the structure. The most damage with average value 1.67and 1.69 that occur on the second and third of track, start from track 34-67 and 68-100. The postiton is located in point 33-66 m dan 67-99 m from Surabaya (north of bridge). Mapping result of cracking and release structure showing that 90 percent of pavement on SoekarnoHatta's bridge are damage. Water seepage that occur when the water breaking through the subsurface layers (asphalt) until concrete layer in base ground by content wet materal. Data distribution of pavement area that most occur water seepage on track 35-67 it's on point 33-66 m.
\end{abstract}

Keywords: Pavement; Truss Bridge; Ground Penetrating Radar (GPR) Method

\begin{abstract}
Abstrak
Penelitian ini bertujuan untuk mengeksplorasi dan menganalisis kondsi struktur lapisan perkerasan jalan pada jembatan rangka baja Soekarno-Hatta Malang dengan metode Ground Penetratig Radar (GPR). GPR digunakan untuk mengetahui jenis material objek berdasarkan konstanta dielektrik yang dimiliki setiap material, serta untuk melihat adanya defomasi, retak, pelepasan struktur, serta rembesan air. Pengumpulan data dilakukan dengan menggunakan teknik observasi lapangan dan pengambilan data sampel pada 101 titik lintasan di analisis dengan teknik deskriptif kuantitaif menggunakan Ms.Excel, notepad, paint, software GeoScan32, dan di interpretasikan dalam software Surfer 9.0. Hasil penelitian menunjukkan bahwa struktur perkerasan jalan terdiri dari perkerasan lentur aspal dan perkerasan kaku beton yang diketahui berupa lantai kendaraan dengan jenis material pada perkerasan yang dapat teridentifikasi adalah aspal kering, aspal basah, beton kering, beton basah,dan adanya udara dipemukaan. Deformasi terjadi pada semua lintasan dan di beberapa titik lintasan teridentifikasi mengalami retak dan pelepasan struktur. Kerusakan terbanyak dengan nilai rata-rata 1,67 dan 1,69 diketahui terjadi pada bagian yang kedua dan ketiga, yaitu dimulai pada lintasan ke 34-67 dan 68-100. Posisi terletak pada bentang ke 33-66 meter dan 67-99 meter dari arah Surabaya (utara jembatan). Hasil pemetaan retak dan pelepasan lapisan menunjukkan 90 persen dari perkerasan jalan pada Jembatan Soekaro-Hatta telah mengalami kerusakan. Rembesan terjadi ketika air menerobos lapisan permukaan (aspal) bagian bawah hingga menembus lapisan beton di dasar permukaan dengan indikator konten material basah. Data persebaran daerah perkerasan jalan yang banyak mengalami rembesan air terjadi pada lintasan 35-67 yaitu pada posisi bentang ke 33-66 meter.
\end{abstract}

Kata kunci: Perkerasan jalan; Jembatan Rangka; Metode Ground Penetrating Radar (GPR) 


\section{Pendahuluan}

Kondisi jalan dan jembatan akan mengalami penurunan fungsi struktural seiring dengan bertambahnya umur rencana konstruksi. Peningkatan volume kendaraan yang melewati jalan juga akan meningkatkan beban yang harus di dukung oleh jembatan (Sianturi dkk.,2013). Perkerasan jalan merupakan bagian utama dari struktur atas jembatan yang terdiri dari beberapa lapisan material yang dipadatkan (Dirjen Bina Marga, 2011) diatas tanah dasar atau tumpuan dengan maksud agar lalu lintas dapat berjalan dengan lancar tanpa terhambat. Perkerasan jalan pada jembatan terdiri dari lapis permukaan dengan material aspal dan lapis perkerasan beton sebagai lantai jembatan. Perkerasan jalan yang baik mempunyai beberapa kriteria yang harus dicapai sesuai dengan standar fungsinya. Lapis permukaan pada perkerasan jalan harus kedap terhadap air, stabil, permukaan tidak licin, rata tidak bergelombang, tidak terdapat bagian yang mengalami cacat permukaan, defomasi, dan retak (Dirjen Bina Marga, 2009).

Kegagalan struktural menunjukkan adanya kerusakan pada satu atau lebih komponen yang membuat struktur perkerasan tidak mampu untuk menahan beban lalu-lintas yang lewat di atas lapisan permukaan. Di Indonesia belum banyak metode yang secara khusus digunakan untuk mengevaluasi bagian perkerasan jalan secara keseluruhan. Metode yang sering digunakan selama ini terbatas pada pemeriksaan visual pada bagian permukaan seperti yang dilakukan oleh Bina Marga provinsi Jawa Timur. maka diperlukan metode geofisika Ground Penetrating Radar (GPR) untuk mengksplorasi dan kondisi perkerasan jalan.

\section{Metode}

Penelitian ini dilakukan pada bulan Maret 2015 dengan mengambil sampel data dalam 101 lintasan di area jembatan rangka baja Soekarno-Hatta, kecamatan Lowokwaru, kodya Malang. Secara geografis lokasi jembatan terletak pada koordinat 07056'58"S dan $112^{\circ} 36^{\prime} 57.2$ " E. Alat yang digunakan dalam penelitian ni adalah GPR OKO AB-1200. Penelitian ini menggunakan rancangan deskriptif kuantitaif, dimana data penelitian merupakan paparan visual berupa interpretasi dalam bentuk gambar yang diproses ke dalam angka. Pengumpulan data menggunakan teknik observasi lapangan dan pengambilan data yang diawali dengan studi pustaka.

Kegiatan analisis data dimulai dari tahap pengolahan menggunakan Ms.Excel, notepad, software GeoScan32, software Surfer 9.0, tahap identifikasi dan klasifikasi, tahap interpretasi data, dan tahap evaluasi data. Analisis software GeoScan32 digunakan untuk mengetahui daerah yang mengalami deformasi struktur dan menghitung nilai dielektrik (epsilon) dalam menentukan jenis material yang berada di bawah permukaan perkasan jalan. Sedangkan software Surfer 9.0 digunakan dalam menginversi data agar hasil scanning dapat diinterpretasikan dalam bentuk penampang yang lebih jelas.

\section{Hasil dan Pembahasan}

Data yang telah diolah merupakan data mentah hasil scanning GPR. Hasil tersebut sebagai refleksi gelombang elektromagnetik yang dipancarkan oleh transmitter ketika melalui batas medium yang kemudian diterima oleh receiver. Data yang ditampilkan dalam bentuk radargram merupakan fungsi waktu, jarak dan kedalaman. 


\section{Gambar 1. Radargam Hasil Scanning Software GeoScan32 pada GPR}

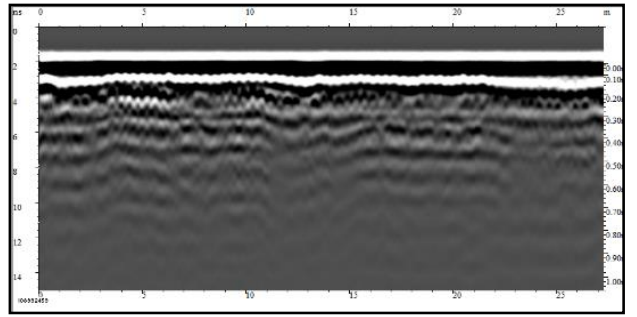

Data hasil scanning software GeoScan32 kemudian di proses dengan menggurangi hasil filtering untuk menunjukkan citra sebenarnyanya sebagai analisis struktur untuk mendapatkan pola deformasi, retak dan pelepasan struktur.

Gambar 2. Hasil pengolahan GeoScan32 untuk mendapatkan pola deformasi, retak, dan pelepasan struktur

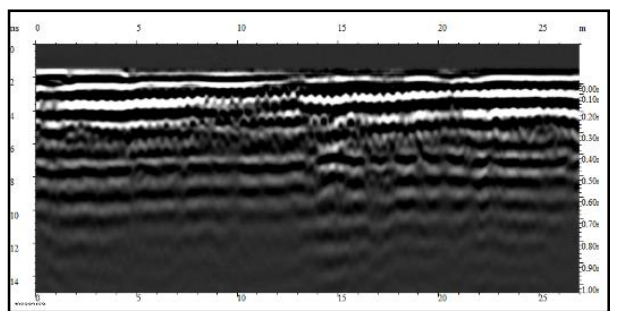

Ciri-ciri yang ditunjukkan bahwa struktur lapisan mengalami deformasi adalah dengan adanya pola kerusakan seperti pada acuan standar berikut.

\section{Gambar 3. Pola Deformasi pada Perkerasan Jalan}

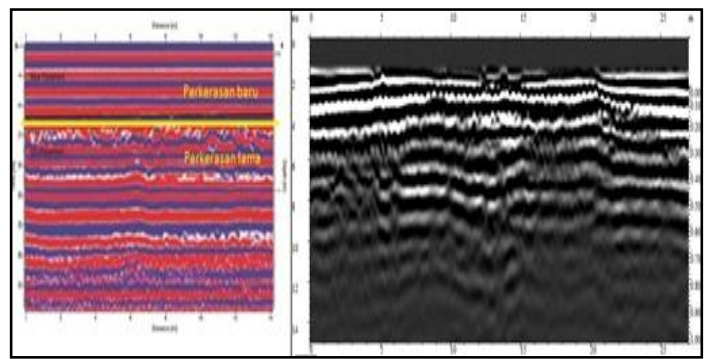

Gambar 3 sisi kiri merupakan data acuan standar yang digunakan sebagai pembanding dengan data hasil penelitian sisi kanan. Secara keseluruhan deformasi terjadi pada semua lintasan. Gambar sisi kiri berlabel "perkerasan lama", menunjukkan adanya perubahan bentuk perkerasan jalan jika dibadingkan dengan bagian kiri berlabel "perkerasan baru", maka pada Gambar 3 sisi kanan dapat dikatakan telah mengalami deformasi seperti daerah perkerasan lama.

Analisis deformasi digunakan untuk menganalisis struktur yang dapat dilihat secara langsung dengan hasil scanning radargram. Selain terdeformasi dari bentuk aslinya terdapat beberapa titik yang mengalami penurunan terhadap bidang lurus struktur lapisan yang dapat 
dikatakan sebagai retak, dan pelepasan struktur lapisan. Pola-pola tersebut ditandai dengan lingkaran dan tanda panah merah dalam Gambar 4.

\section{Gambar 4. Pola Deformasi}

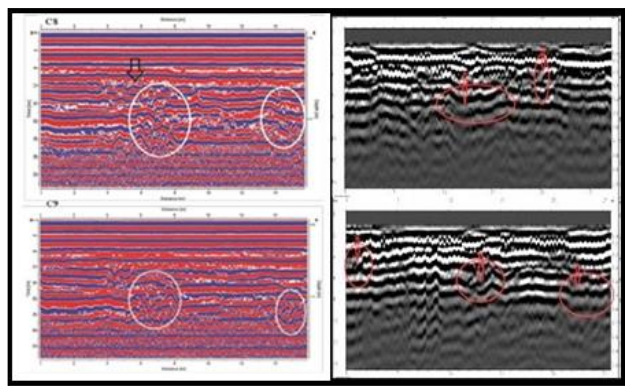

Persebarannya dapat ditunjukkan oleh grafik pada Gambar 5.

Gambar 5. Data persebaran titik yang mengalami retak dan pelepasan struktur

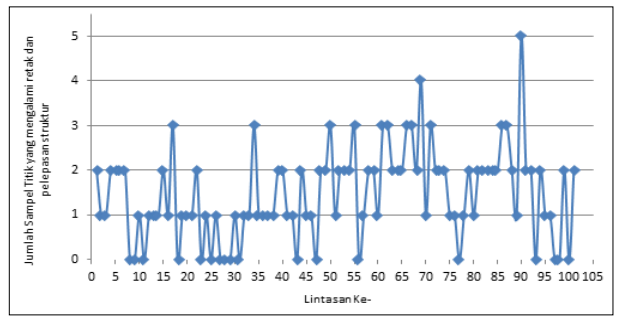

Titik-titik yang banyak mengalami kerusakan dengan nilai rata-rata 1,67 dan 1,69 diketahui terjadi pada bagian yang kedua dan ketiga, mulai dari rentang lintasan ke 34-67 dan 68-100. Posisi terletak pada bentang ke 33-66 meter dan 67-99 meter dari arah Surabaya (utara jembatan). Hasil pemetaan retak dan pelepasan lapisan juga menunjukkan $90 \%$ dari perkerasan jalan pada Jembatan Soekaro-Hatta telah mengalami kerusakan.

Informasi jenis material yang berada di bawah permukaan dapat diketahui dari nilai dielektrik (epsilon) pada software Surfer 9.0.

\section{Gambar 6. Konstanta dielektrik dan jenis material}

\begin{tabular}{|c|c|c|c|c|}
\hline 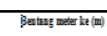 & 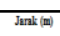 & Rethinuman (it) & Epplatef $\mathrm{F}$ al & Jaid Ihtarial \\
\hline 0 & \multirow[t]{5}{*}{ W.S } & 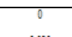 & 0.05 & 0 \\
\hline & & 0.05 & 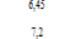 & $A_{A B}$ \\
\hline & & $0,0,5$ & 8.1. & ${ }_{B K}$ \\
\hline & & 0.15 & 6.3 & $\mathrm{BR}$ \\
\hline & & 0.25 & $\$, 9$, & $\mathrm{Bg}$ \\
\hline & \multirow[t]{6}{*}{ 1., } & 0 & 0,8 & $\mathrm{v}$ \\
\hline & & 0,005 & $2: 32$ & $A B$ \\
\hline & & 0,05 & 6,12 & $A B$ \\
\hline & & 0,075 & 3,2 & $A B$ \\
\hline & & 0,15 & 5.95 & $\mathrm{gR}$ \\
\hline & & 0.25 & 6,5 & $\mathrm{BK}$ \\
\hline
\end{tabular}


Data pada Gambar 6 telah dibandingkan dengan konstanta dielektrik yang ada dan disesuaikan dengan kondisi aktual daerah penelitian dan beracuan pada SNI Konstruksi Jembatan serta Pedoman Pemeiksaan Jembatan Rangka Baja.

Berdasarkan tabel data pada Gambar 6 disajikan gambar penampang bawah permukaan perkerasan jalan di jembatan Soe-Hat menggunakan software Surfer 9.0 seperti pada Gambar 7.

\section{Gambar 7. Hasil penampang per lintasan menggunakan software Surfer 9.0}

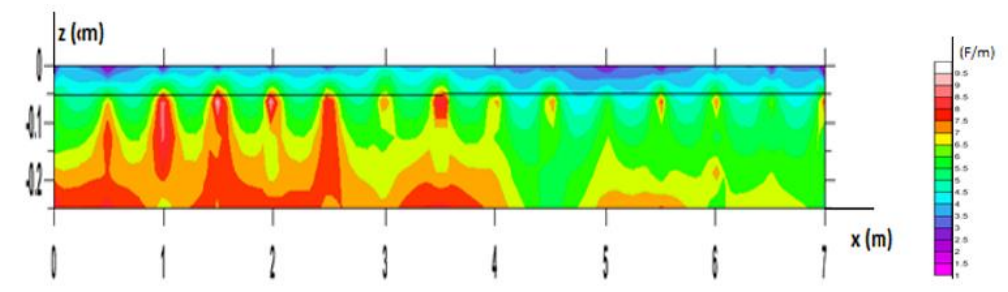

$\mathrm{z}$ merupakan kedalaman perkerasan jalan dengan satuan $\mathrm{cm}$, dan x sebagai jarak lintasan dengan satuan meter. Indikator warna yang berada pada kanan gambar merupakan nilai dielektrik (epsilon).

Rembesan terjadi ketika konten material basah ditemukan di daerah permukaan (aspal) bagian bawah hingga menembus lapisan beton dasar permukaan. Aspal basah mempunyai nilai dielektrik 5-12 F/m yang di tunjukkan oleh warna hijau. Rembesan yang menunjukkan beton basah mempunyai nilai dielektrik lebih dari $10 \mathrm{~F} / \mathrm{m}$ dengan indikator warna putih. Pada Gambar 4.8 menunjukkan sebaran rembesan yang terjadi pada semua lintasan dengan kedalaman 0,05 meter, 0,075 meter, dan 0,25 meter. Posisi kedalaman 0,05 meter merupakan lapisan permukaan (aspal) bagian bawah, posisi 0,075 meter adalah lapisan permukaan atas beton, dan pada kedalaman 0,25 adalah lapisan beton bagian dasar. Berkut merupakan data persebaran rembesan air.

Gambar 8. Persebaran titik yang Mengalami Rembesan pada Setiap Kedalaman Lintasan

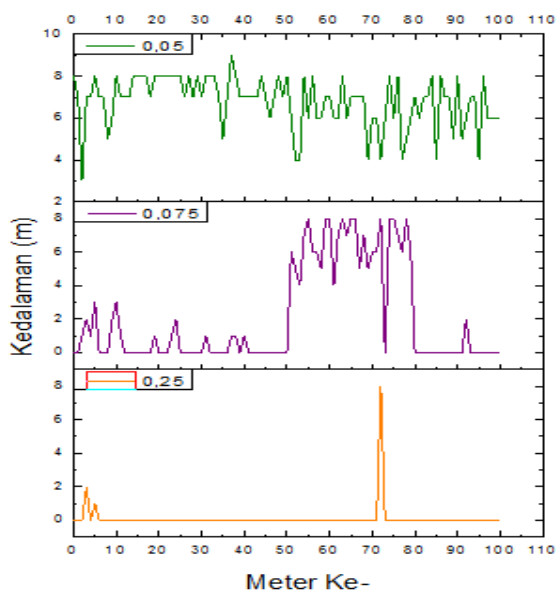




\section{Gambar 9. Hasil Rembesan Air pada Semua Lintasan}

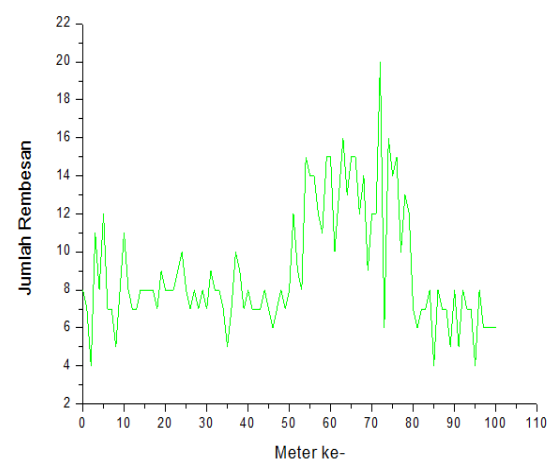

Grafik pada Gambar 8 di plot scara keseluruhan untuk mendapatkan hasil akhir persebaran pada semua lintasan. Hasil plot grafik dapat ditunjukkan pada Gambar 9. Berdasarkan Grafik pada Gambar 8 dan 9 maka dperoleh nilai rembesan rata-rata yang ditabelkan pada Tabel 1.

Tabel 1. Jumlah Rata-rata Nilai Rembesan Air pada Semua Lintasan

\begin{tabular}{llllll}
\hline \multirow{2}{*}{$\begin{array}{l}\text { Lintasan } \\
\text { Ke- }\end{array}$} & $\begin{array}{l}\text { Posisi } \\
\text { Bentang Ke } \\
\text { (meter) }\end{array}$ & $\begin{array}{l}\text { Jumlah Rata-rata Rembesan Per } \\
\text { Kedalaman }\end{array}$ & $\begin{array}{l}\text { Jumlah Rata- } \\
\text { Rata Rembesan } \\
\text { Semua Lintasan }\end{array}$ \\
\cline { 2 - 5 } & 0.05 & 0.075 & 0.25 & 7.970 \\
\hline s/d 34 & 1 s/d 33 & 7.333 & 0.545 & 0.091 & 10.061 \\
68 s/d 67 100 & 34 s/d 66 & 6.788 & 3.273 & 0 & 8.970 \\
\hline
\end{tabular}

Nilai rata-rata rembesan terbanyak terjadi pada lintasan ke 35 pada posisi bentang mulai dari 34 meter.

Pavement distress merupakan kerusakan yang terjadi pada lapisan perkerasan lentur (aspal) akibat kelelahan material yang berpengaruh terhadap deformasi dalam berbagai bentuk. Menurut Watmove (2007) pengaruh merembesnya air ke pori-pori perkerasan karena drainase jalan yang tidak berfungsi dengan baik. Hasil peelitian juga menunjukkan adanya hubungan kegagalan struktur yang terjadi antara deformasi, retak, pelepasan struktur, yang berakibat pada merembesnya air pada lapisan-lapisan dasar. Banyak tipikal kerusakan struktur perkerasan yang tidak hanya diakibatkan oleh air. Kerusakan perkerasan dapat terjadi karena kualitas aspal atau beton yang rendah, adanya pengaruh momen lentur, tegangan tarik, dan beban kendaraan yang berlebih (Dirjen Bina Marga, 2009).

\section{Simpulan}

\subsection{Kesimpulan}

Struktur lapisan perkerasan jalan pada jembatan rangka baja Soekarno-Hatta Malang terdiri dari perkerasan lentur aspal dan perkerasan kaku beton yang diketahui berupa slab lantai kendaraan, dengan jenis material pada perkerasan yang dapat teridentifikasi berupa aspal kering, aspal basah, beton kering, beton basah,dan udara dipemukaan. Hasil analisis menunjukan telah terjadi deformasi dari bentuk asli perkerasan jalan pada semua lintasan dan dalam beberapa titik sampel lintasan diperkirakan adanya kontur bawah permukaan yang mengalami retak dan pelepasan struktur lapisan. Kerusakan jenis retak dan pelepasan struktur 
terbanyak dengan nilai rata-rata 1,67 dan 1,69 diketahui terjadi pada bagian yang kedua dan ketiga, yaitu dimulai pada lintasan ke 34-67 dan 68-100. Posisi terletak pada bentang ke 3366 meter dan 67-99 meter dari arah Surabaya (utara jembatan). Hasil pemetaan retak dan pelepasan lapisan menunjukkan $90 \%$ dari perkerasan jalan telah mengalami kerusakan. Data persebaran daerah perkerasan jalan yang banyak mengalami rembesan air terjadi pada lintasan 35-67 yaitu pada posisi bentang ke 33-66 meter.

\subsection{Saran}

Mengingat dengan adanya kondisi yang terjadi di lapangan, maka diaharapkan adanya kajian ulang terhadap jembatan oleh pemerintah agar tidak terjadi dampak negatif yang lebih kompleks dari adanya rembesan air dan kerusakan pada perkerasan jalan. Berdasarkan data laporan pengecekan triwulan oleh Bina Marga diharapkan segera memperbaiki lubang-lubang yang telihat secara visual agar tidak menyebabkan kerusakan pada perkerasan yang lain dan sesuai dengan tujuan UU RI Nomor.34. Serta perlu adanya alternatif perbaikan serta peningkatan umur jalan seperti diberi pelapisan ulang dan memeriksa saluran drainase.

\section{Daftar Rujukan}

Cao, et al. (2007). Implemetation of Ground Penetrating Radar. Local Road Research Board of Minesota, Departement of Transportation Ierland.

Dirjen Bina Marga. (2009). Pedoman Konstruksi dan Bangunan, Pemeriksaan Jembatan Rangka Baja. Jakarta: Kementrian Jendral Bina Marga.

Imansyah, M. D., Anwar, F. H., Budio, S. P., \& Roland Martin, S. (2016). Analisis Kemanan Jembatan Rangka Baja Soekarno-Hatta Malang Ditinjau dari Aspek Kesehatan, Tegangan Pelat Buhul, dan Simulasi Kebakaran. Universitas Brawijaya: Fakultas Teknik, Jurusan Teknik Sipil.

Irzami. (2010). Penilaian kondisi perkerasan dengan menggunakan metode indeks kondisi perkerasan Pada ruas jalan simpang kulim - simpang batang. Disertasi. Pekanbaru: PPs Universitas Islam Riau.

Lubis, M. E., \& Sianturi, N. M. (2013). Perilaku dan sistem struktur rangka baja jembatan. Jurnal Rancang Sipil, 2(1), 50-57

Republik Indonesia,.(2004). Undang-Undang No. 38 tahun 2004 tentang Jalan, Sekretariat Negara Republik Indonesia.

Transportation Officials. (1993). AASHTO Guide for Design of Pavement Structures, 1993 (Vol. 1). Aashto.

Wightman, et al. (2003). Application of Geotechnical Method to Highway Related Problems, (DTFH68-02-P-00083). Lakewood: Federal Highway Administration. 